\title{
Evaluation of emergency department ultrasound machines for the presence of occult blood
}

\author{
Zafrina Poonja, BSc, MD*ף; Jasmene Uppal, BSc ${ }^{\dagger}$; Stuart J. Netherton, PhD, MD*; Rhonda Bryce, \\ MSc, MD ${ }^{\ddagger}$; Andrew W. Lyon, $\mathrm{PhD}^{\S}$; Bruce Cload, PhD, MD*
}

\author{
CLINICIAN'S CAPSULE \\ What is known about the topic? \\ Bedside ultrasound is a frequently used tool in the \\ emergency department (ED), with no standard cleaning \\ protocols in place. \\ What did this study ask? \\ Is there visible and occult contamination of the ED \\ ultrasound machine after daily use and in trauma? \\ What did this study find? \\ This study found that the ultrasound machine tested \\ positive for occult blood contamination on $10 \%$ of daily \\ tests and on $43 \%$ of assessments after use in trauma. \\ Why does this study matter to clinicians? \\ Standard cleaning practices should be implemented to \\ reduce contamination rates.
}

\section{ABSTRACT}

Objectives: Bedside ultrasound in the emergency department is a common diagnostic tool, especially when evaluating trauma patients. Many trauma patients have blood on their chest and abdomen that may contact the probe during examination. The primary aim of this study was to investigate whether occult blood contamination was present on the emergency department ultrasound machine, both after daily use and after use in trauma. Methods: For a period of 31 days, the ultrasound machine at the trauma centre emergency department in Saskatoon, Saskatchewan, was tested once daily and following all Level 1 traumas. The ultrasound machine probes and keyboard were swabbed, and contamination was detected using a commercially available phenolphthalein blood testing kit. Any visible blood contamination was also noted. The machine was then cleaned following each positive test and re-tested to ensure the absence of contamination.

Results: Over the study period, the ultrasound machine tested positive for occult blood contamination on $10 \%$ of daily tests and on $43 \%$ of assessments after its use in trauma. The curvilinear probe was most frequently contaminated (daily, $6 \%$; trauma, 26\%), followed by the keyboard (daily, 3\%; trauma, 26\%), but both lacked visible contamination.

Conclusions: In this single centre study, there was evidence of occult blood on the emergency department ultrasound machine after both routine use and major trauma cases, highlighting the need for a standardized cleaning and disinfection protocol.

\section{RÉSUMÉ}

Objectif: L'échographie au chevet du patient est un examen de diagnostic courant au service des urgences (SU), surtout dans l'évaluation de cas de trauma. Bon nombre de blessés ont du sang sur la poitrine et l'abdomen, matière susceptible d'entrer en contact avec la sonde au cours de l'examen. L'étude avait donc pour objectif principal la recherche de contamination par du sang occulte sur l'échographe au SU, et ce, tant après l'utilisation quotidienne de l'appareil qu'après son utilisation dans les cas de trauma.

Méthode: L'échographe utilisé au SU du centre de traumatologie de Saskatoon, en Saskatchewan, a fait l'objet d'analyses une fois par jour et après tous les cas de trauma de niveau I, et ce, sur une période de 31 jours. Des prélèvements ont été effectués par écouvillonnage sur les sondes ainsi que sur le clavier de l'appareil, et la recherche de contamination se faisait à l'aide d'une trousse commerciale d'analyse de sang à base de phénolphtaléine. De plus, toute trace visible de contamination par le sang était notée. L'appareil était nettoyé chaque fois que le résultat était positif, et un nouveau prélèvement était effectué pour s'assurer de l'absence de contamination.

Résultats: Des résultats positifs de contamination par du sang occulte ont été enregistrés, sur toute la période d'étude, dans $10 \%$ des analyses quotidiennes et dans $43 \%$ des évaluations suivant l'utilisation de l'appareil dans les cas de trauma. La sonde curviligne était très souvent contaminée (prélèvement quotidien : $6 \%$; après un trauma : $26 \%$ ), suivie du clavier (prélèvement

From the *Department of Emergency Medicine, College of Medicine, University of Saskatchewan, Saskatoon, SK; †College of Medicine, University of Saskatchewan, Saskatoon, SK; ¥Department of Community Health and Epidemiology, College of Medicine, University of Saskatchewan, Saskatoon, SK; §Department of Pathology and Laboratory Medicine, Saskatchewan Health Authority, Saskatoon, SK; and IDepartment of Emergency Medicine, University of Alberta, Edmonton, AB.

Correspondence to: Dr. Zafrina Poonja, Department of Emergency Medicine, University of Alberta, 790 University Terrace Building, 8303112 Street, Edmonton, AB T6G 2T4; Email: zafrinapoonja@gmail.com 
quotidien : $3 \%$; après un trauma : $26 \%$, mais aucune de ces parties ne portait de trace visible de contamination.

Conclusion: Il ressort de cette étude monocentrique qu'il y avait présence de sang occulte sur l'appareil d'échographie au SU, tant après son utilisation quotidienne qu'après son utilisation dans les cas de trauma grave, d'où la nécessité d'un protocole uniforme de nettoyage et de désinfection.

Keywords: blood contamination, emergency department, occult contamination, ultrasound

\section{INTRODUCTION}

The use of bedside ultrasound in the emergency department (ED) is an everyday practice. Its uses include procedural guidance and providing diagnostic information, particularly in trauma. ${ }^{1,2}$ In trauma, a common application is the extended focused assessment with sonography for trauma (eFAST), which evaluates the patient's peritoneal, pericardial, and pleural spaces for free fluid and lung collapse. ${ }^{3}$

Many trauma patients have blood on their skin in the regions assessed by the eFAST exam. Ultrasound blood contamination is a safety issue for patients and ultrasound users. Despite the lack of apparent gross contamination, practitioners should still practice safe disinfection of the ultrasound after every use, because viruses may be transmitted through dry blood. ${ }^{4}$ The presence of occult blood has been shown on medical equipment that contacts patients. ${ }^{5}$ The incidence of occult blood contamination of ultrasound machines is not known; however, the presence of visible contamination and bacterial colonization has been shown. ${ }^{6,7}$ Therefore, the primary goal of this study is to evaluate the trauma centre ED ultrasound machine for the presence of occult and visible blood contamination after routine daily use and its use in traumas.

\section{METHODS}

This study occurred over a 31-day period (June 15, 2016, to July 15, 2016) at the Royal University Hospital (RUH), the trauma centre in Saskatoon, Saskatchewan. The RUH ED ultrasound machine was tested for visible and occult blood once daily at random times, based on the testers availability, between 0900 and 2359 hours, and after each Level 1 trauma. The machine was inspected for any visible blood and then swabbed to test for occult blood contamination. Four areas on the machine were tested: the linear, cardiac, and curvilinear probes, and the keyboard. If one or more of the four zones were found to be positive for visible or occult blood, the assessment was considered positive. The machine was tested for blood as soon as possible after trauma team use. In our institution, it is the responsibility of the user, not the cleaning staff, to clean the ultrasound machine.

To test for occult blood, the entire ultrasound machine keyboard and probes were swabbed in a predefined pattern using a three-step reduced phenolphthalein test kit based on the Kastle-Meyer reaction (DAVTECH Analytical Services [Canada] Inc.) to test for the presence of hemoglobin on the swab. ${ }^{8}$ If a positive result was returned, the machine was thoroughly cleaned by the tester in a standard protocol with towels and germicidal wipes, then re-tested to ensure the absence of occult blood contamination. See Appendix 1 for further details.

\section{RESULTS}

The ultrasound machine was tested daily 31 times and after 23 Level 1 traumas, resulting in a total of 54 assessments. There was visible blood contamination on two separate occasions, both after a trauma. There was no visible blood contamination on daily inspections. There were three occasions (10\% of daily tests) where occult blood was found on daily inspections and 10 occasions (43\% of post-trauma tests) where occult blood was found after Level 1 traumas (Table 1). For further detail on location and frequency of contamination, see Appendix 2. After cleaning the ultrasound machine when occult or visible blood was detected, the absence of residual occult blood was confirmed $100 \%$ of the time. The ultrasound machine was evaluated for blood within 1 hour of trauma arrival in $82 \%$ of cases, and all tests were completed within 2.5 hours of the trauma team's arrival.

\section{DISCUSSION}

Our results show the presence of visible and occult blood on our ultrasound machine, primarily after traumas. The risk of transmitting a virus through ultrasound procedures is possible ${ }^{4}$; however, we did not attempt to look for the presence of any blood borne viruses from the samples, because this was not within 


\begin{tabular}{|c|c|c|c|}
\hline Test & Positive* daily tests & Positive* post-trauma tests & Proportion positive, ${ }^{*}$ combined \\
\hline Visible blood observed & $0 / 31(0 \%)$ & 2/23 (9\%) & 2/54 (4\%) \\
\hline Occult blood detected & $3 / 31(10 \%)$ & $10 / 23(43 \%)$ & $13 / 54(24 \%)$ \\
\hline
\end{tabular}

the scope of this study. Occult blood has been shown to be present on medical equipment that contacts patients, ${ }^{5}$ and ultrasound probes have been shown to be contaminated with visible blood, used gel, ${ }^{6}$ and bacteria. $^{7}$ Although ours is a small study, we feel it adds to the literature that highlights the importance of ultrasound cleaning in the ED. With increasing ultrasound usage, the potential for iatrogenic infection, while still small, may increase. This calls for ultrasound user education and departmental protocols with standard cleaning/disinfecting techniques. Cleaning protocols should be enacted for routine cleaning after every patient encounter. The tools to properly clean the ultrasound machine are already present in the ED, and, although remembering to clean the machine during a busy shift may not be automatic, a protocolized methodology may help improve the machine's cleanliness. Our finding that germicidal wipes were able to remove all traces of occult blood during the study suggests that this is not difficult to accomplish.

\section{LIMITATIONS}

Foremost, this is a single centre, small observational study. We feel the results are valid; however, for more generalizable conclusions, this type of investigation would need to be expanded to multiple trauma centres.

We assumed that the ultrasound was used during each trauma; although, we did not formally document evidence of its use. If the ultrasound was not actually used in all trauma evaluations, the true proportion of trauma-related ultrasound contaminations is expected to be even higher.

Because daily swab assessments were performed only once per day, it is possible that periods of contamination were missed between swabs and that residual contamination from daily use was actually present prior to trauma use. Although this may be a consideration, we feel it does not affect conclusions. If this were true, however, then having occult blood present from daily use is even more alarming.

As with any chemical testing procedure, the potential exists for false negatives and false positives. This is a well-defined procedure for the detection of occult blood, ${ }^{8}$ and similar studies have been published using the same testing strategy. ${ }^{5}$ We feel that the unlikely potential for false negatives and false positives does not impact the overall conclusions of this study.

\section{CONCLUSION}

In this single centre study, there was evidence of occult blood on the ED ultrasound machine after routine use and major trauma cases, highlighting the need for a standardized cleaning and disinfection protocol.

\section{Competing interests: None declared.}

Financial support: This research received support from the University of Saskatchewan College of Medicine (Dean's Summer Student Research Project 2016). This study received no funding from commercial sources.

\section{SUPPLEMENTARY MATERIALS}

To view supplementary material for this article, please visit https://doi.org/10.1017/cem.2018.447

\section{REFERENCES}

1. Henneberry RJ, Hanson A, Healey A, et al. Use of point of care sonography by emergency physicians. CFEM 2012;14 (2):106-2, doi:10.2310/8000.

2. Kim DJ, Theoret J, Liao MM, et al. The current state of ultrasound training in Canadian emergency medicine programs: perspectives from program directors. Acad Emerg Med 2012;19(9):1073-8, doi:10.1111/j.15532712.2012.01430.x.

3. Rippey JC, Royse AG. Ultrasound in trauma. Best Pract Res Clin Anaesthesiol 2009;23(3):343-62. 
4. Nyhsen CM, Humphreys H, Nicolau C, et al. Infection prevention and ultrasound probe decontamination practices in Europe: a survey of the European Society of Radiology. Insights Imaging 2016;7(6):841-7, doi:10.1007/s13244-016-0528-z.

5. Hall JR. Blood contamination of anesthesia equipment and monitoring equipment. Anesth Analg 1994;78(6):1136-9.

6. Sanz GE, Theoret J, Liao MM, et al. Bacterial contamination and cleanliness of emergency department ultrasound probes. CFEM 2011;13(6):384-9, doi:10.2310/8000.2011.110409.
7. Shokoohi H, Armstrong P, Tansek R. Emergency department ultrasound probe infection control: challenges and solutions. Open Access Emerg Med 2015;7:1-9. doi:10.2147/ OAEM.S50360.

8. Louie RF, Lau MJ, Lee JH, et al. Multicenter study of the prevalence of blood contamination on point-of-care glucose meters and recommendations for controlling contamination. Point Care 2005;4(4):158-63, doi:10.1097/01. poc.0000189933.35225.77. 